\title{
MicroRNA-429 inhibits neuroblastoma cell proliferation, migration and invasion via the NF-kB pathway
}

\author{
Xianjun Zhou ${ }^{1}$, Hongting Lu' ${ }^{1}$ Fujiang Li ${ }^{1}$, Xiwei Hao ${ }^{1}$, Lulu Han ${ }^{2}$, Qian Dong ${ }^{1^{*}}$ and Xin Chen ${ }^{{ }^{*}}$
}

\author{
* Correspondence: 18661801885@ \\ 163.com; 15506399877@163.com \\ 'Department of Pediatric Surgery, \\ the Affiliated Hospital of Qingdao \\ University, No.16 Jiangsu Road, \\ Qingdao 266000, Shandong, China \\ Full list of author information is \\ available at the end of the article
}

\begin{abstract}
Background: MicroRNAs (miRNAs or miRs) can participate in the development and progression of neuroblastoma. Many studies have indicated that miR-429 can participate in tumor development. However, the mechanism underlying miR-429mediated progression of neuroblastoma remains largely unclear.
\end{abstract}

Methods: Colony formation and apoptosis assays were used to determine the effect of miR-429 on cell proliferation. Its impact on cell migration was determined using the wound-healing and Transwell assays. The target gene of miR-429 was confirmed via western blotting and luciferase reporter assays. A nude mouse xenograft model with miR-429 overexpression was used to assess the effect on tumor growth.

Results: Our findings indicate that miR-429 is downregulated in neuroblastoma cell lines. We also found that it can induce apoptosis and inhibit proliferation in cells of those lines. MiR-429 can bind to the 3'-UTR of IKK 3 mRNA and overexpression of IKK $\beta$ can reverse cell proliferation, blocking the effect of miR-429. Furthermore, miR429 overexpression inhibited neuroblastoma growth in our nude mouse xenograft model.

Conclusion: We provide important insight into miR-429 as a tumor suppressor through interaction with IKK , which is a catalytic subunit of the IKK complex that activates NF-kB nuclear transport. Our results demonstrate that miR-429 may be a new target for the treatment of neuroblastoma.

Keywords: Neuroblastoma, NF-KB signaling, miR-429, IKK $\beta$

\section{Introduction}

Neuroblastoma, which is a malignancy with high mortality, originates from neural crest pluripotent cells [1-3].. It has a high incidence in children under the age of 15 [4]. Treatment primarily involves surgery, but the recurrence rate is very high [5]. Although great progress has been made in clinical treatment, the survival rate of patients with metastatic neuroblastoma has not been improved [6]. Studies have shown that environmental endocrine disruptors may be involved in the disease's progression [7]. Clarifying the mechanisms underlying neuroblastoma progression is necessary for development of more effective treatments.

NF- $\mathrm{KB}$ is upregulated in many blood and solid tumors [8], including neuroblastoma [9]. The NF-kB dimer, which acts as a transcription factor in the nucleus, is isolated in

(c) The Author(s). 2020 Open Access This article is distributed under the terms of the Creative Commons Attribution 4.0 International License (http://creativecommons.org/licenses/by/4.0/), which permits unrestricted use, distribution, and reproduction in any medium, provided you give appropriate credit to the original author(s) and the source, provide a link to the Creative Commons license, and indicate if changes were made. The Creative Commons Public Domain Dedication waiver (http://creativecommons.org/ publicdomain/zero/1.0/) applies to the data made available in this article, unless otherwise stated. 
the cytoplasm in an inactive form that binds to an inhibitor of kappa B protein (IkB), usually IkBa. IKK phosphorylates IkBa, which is then degraded by the proteasome, allowing the NF- $\mathrm{KB}$ dimer to translocate [10]. IKBKB (IKK $\beta)$, which is a catalytic subunit of the IKK complex, activates NF- $\mathrm{KB}$ nuclear transport [11-13]. It is reported that activation of NF- $\mathrm{KB}$ signaling promotes tumorigenesis, progression and therapeutic resistance [14-18]. NF-kB can inhibit apoptosis of tumor cells by activating the transcription of anti-apoptotic genes [19].

Recent improvements in high-throughput gene expression analysis have revealed that microRNAs (miRNAs or miRs) can manipulate local or global gene expression via mRNA cleavage [20]. Endogenous miRNAs are involved in cell development, proliferation and apoptosis [21]. The occurrence of various tumors, including neuroblastoma, is often accompanied by dysregulated expression of specific miRNAs [22-24]. Previous studies have shown that miR-429 inhibits tumor development by binding to c-myc and PLGG1 in gastric and breast cancers [25, 26]. miR-429 also plays a tumor suppressing role in osteosarcoma [27]. However, few studies have investigated the detailed mechanisms of miR-429 in neuroblastoma.

In this study, we investigate the role of miR-429 in neuroblastoma, including its biological function in cells of the SK-N-SH and SH-SY5Y lines. Our findings show that miR-429 overexpression inhibits neuroblastoma cell proliferation and migration and promotes apoptosis. MiR-429 can directly target the 3 '-untranslated region (3'-UTR) and suppress IKK $\beta$ in vivo and in vitro. Thus, miR-429 might play an important role in inhibiting the progression of neuroblastoma.

\section{Materials and methods}

\section{Cell culture and transfection}

Human neuron cells (ScienCell, cat. no. 1520) were cultured in Dulbecco's modified Eagle's neuronal medium (DMENM; cat. no. 1521). Cells of the human neuroblastoma cancer lines IMR-32, SK-N-SH and SH-SY5Y were cultured in Dulbecco's modified Eagle's medium (DMEM; Thermo Fisher Scientific, cat. no. 11995040) supplemented with $10 \%$ fetal bovine serum at $37^{\circ} \mathrm{C}$ in a humidified incubator with $5 \% \mathrm{CO}_{2}$. MiR-429 mimics, control, inhibitor and plasmids were purchased from GenePharma. Cells were transfected with the miR-429 mimic, inhibitor or pcDNA3.1-IKK $\beta$ using Lipofectamine 3000 (Thermo Fisher Scientific) according to the manufacturer's instructions.

\section{Extraction of total RNA and quantitative real-time PCR}

Total RNA was extracted with Trizol (Invitrogen). cDNA was synthesized using MMLV reverse transcriptase (Promega), and mRNA quantitative detection was performed using a StepOne Real-Time PCR system and fast SYBR Green Master Mix (Applied Biosystems). Primers were synthesized by Invitrogen. The PCR conditions were: $94^{\circ} \mathrm{C}$ for $2 \mathrm{~min}$, followed by 30 cycles of $94^{\circ} \mathrm{C}$ for $30 \mathrm{~s}, 60^{\circ} \mathrm{C}$ for $30 \mathrm{~s}$ and $72^{\circ} \mathrm{C}$ for $1 \mathrm{~min}$, and finally $72{ }^{\circ} \mathrm{C}$ for $10 \mathrm{~min}$.

The relative expression level of mRNA was calculated using the $2^{-\Delta \Delta \mathrm{Cq}}$ method. The primers were: miR-429 forward, 5'-CTAACCGACCCAGAAATAAGCG-3' and reverse, 5'-TATCGGCCATGCTCCGGAAAGG-3'; U6 forward, 5'-GATTACAGC CGAACGTGTAGGAA-3' and reverse, 5'-AGCTTGATCGTTTCTCTGGCCACC-3'; 
IKK $\beta$ forward, 5'-GCCAGAAAACATCGTCCT-3' and reverse, 5'-CACCGTTCCA TTCAAGTC-3'; cyclinD1 forward, 5'-AGGAGAACAAACAGATCA-3' and reverse, 5'-TAGGACAGGAAGTTGTTG-3'; IL-8 forward, 5'-AACATGACTTCCA AGCTGGCCG-3' and reverse, 5'-CAGTTTTCCTTGGGGTCCAGAC-3'; Bcl-2 forward, 5' -AGCAGCAAGTAGGTGTCCCAG-3' and reverse, 5'-CTCCACGCCAT CTTGCTTCT-3'; and GAPDH forward, 5'-TCCAGAGTGCAAGGCTTCAG-3' and reverse, 5'-GACAGCACGCAGTAGCAGTAG-3'.

\section{Western-blotting}

The protein in the cell lysates was separated via SDS-PAGE and transferred to nitrocellulose membranes (micropores). Primary antibodies (Abcam) targeting the following proteins were applied: IKK $\beta$ (cat. no. ab124957, 1:2000), cyclinD1 (cat. no. ab16663, 1: 2000), Bcl-2 (cat. no. ab59348, 1:2000), IL-8 (cat. no. ab18672, 1:2000), and GAPDH (cat. no. ab9485, 1:1000). An IRDye-labeled donkey anti-mouse or rabbit anti-IgG (Licor Biosciences) was used as the secondary antibody, and the membrane was assayed with an Odyssey Infrared Imaging System (Gene Company Limited).

\section{Cytotoxicity assay}

Cell proliferation was determined using a Cell Counting Kit-8 (CCK-8). Cells were seeded in $100 \mu \mathrm{l}$ of medium supplemented with $10 \% \mathrm{FBS}$ at $5 \times 10^{4}$ cells/well in 96-well plates. After $48 \mathrm{~h}$ incubation, $10 \mu \mathrm{l}$ of CCK- 8 reagent was added to each well and the cells were cultured for $1 \mathrm{~h}$ at $37^{\circ} \mathrm{C}$ in a humidified incubator with $5 \% \mathrm{CO}_{2}$. The absorbance at $450 \mathrm{~nm}$ was measured with a microplate reader (Bio-Tech Company).

\section{Colony formation assay}

After the cells were transfected with miR-429 mimic or inhibitor, they were cultured in a 6-well plate for 10 days. The colonies were fixed with methanol for $30 \mathrm{~min}$ and stained with $1.0 \%$ crystal violet for $20 \mathrm{~min}$.

\section{Scratch-healing migration assay}

Briefly, cells were seeded at $5 \times 10^{4}$ cells/well in 24-well plates and cultured for $24 \mathrm{~h}$. Wounds were created using a $10-\mu \mathrm{l}$ pipette tip. Wound healing was assessed after $24 \mathrm{~h}$. We randomly selected 5 locations for assessment and photographing. Images were obtained with a Zeiss Axiovert 200 microscope.

\section{Cell invasion assay}

Briefly, $5 \times 10^{4}$ cells were added into the upper chamber of a Transwell, and then, 0.7 $\mathrm{ml}$ DMEM was added to the lower chamber. Cells were cultured for $24 \mathrm{~h}$ at $37^{\circ} \mathrm{C}$ in a humidified incubator with $5 \% \mathrm{CO}_{2}$. After treatment, the cells were fixed with methanol for $30 \mathrm{~min}$ and stained with $1.0 \%$ crystal violet for $20 \mathrm{~min}$. The number of invasive cells penetrating the Matrigel was recorded.

\section{Cell apoptosis assay}

Cells transfected with the miR429 mimic, inhibitor or control were incubated for $48 \mathrm{~h}$ and then collected. Cells were analyzed for double staining with FITC Annexin V and 
PI using a FITC Annexin V Apoptosis Detection Kit and CellQuest software (both from BD Biosciences) according to the manufacturer's protocol.

\section{Luciferase reporter assay}

The 3'-UTR of IKK $\beta$ was synthesized and inserted into pMIR-REPORT. Cells were transfected with miR-429 mimic as indicated $24 \mathrm{~h}$ before transfection with pMIRREPORT-IKK $\beta$. Luciferase activity was measured with a Dual-Luciferase Reporter Assay System (Promega).

\section{Immunohistochemistry}

Tumor sections were incubated with antibody against IKK $\beta$ (1:150) overnight, washed three times with PBS containing 0.05\% Tween, incubated for $2 \mathrm{~h}$ at room temperature, and washed three times with PBS containing $0.05 \%$ Tween. The sections were then visualized with 3,3'-diaminobenzidine (DAB) substrate and counterstained with hematoxylin QS. Ten fields were selected for imaging under a microscope (Carl Zeiss).

\section{In vivo tumorigenicity assay}

Lentiviruses carrying empty vector (NC) and miR-429 expression vector (miR-429 mimics) were used to infect SH-SY5Y cells that showed stable expression in this study. These were used in an in vivo tumorigenicity assay.

Briefly, 4- to 5-week-old BALB/c nude mice were purchased from Beijing HFK Biotechnology. The mice were housed in a pathogen-free animal facility and randomly assigned to the control or experimental group (five mice per group). Then, $2 \times 10^{6}$ of the NC or miR-429 mimic SH-SY5Y cells were resuspended in $200 \mu \mathrm{l}$ of PBS and subcutaneously injected into the nude mice. The tumor diameter and size were measured every 3-4 days to monitor tumor formation. After euthanasia, the tumor was recovered and the wet weight of each tumor was examined.

\section{Statistical analysis}

All statistical analyses were performed using SPSS 17.0 (SPSS, Chicago, USA) using either one-sample $t$-test or one-way ANOVA. All data are presented as the mean \pm S.E.M. A $p$ value of less than 0.05 was indicated with *, and a $p$ value of less than 0.01 was indicated with $* *$.

\section{Results}

\section{miR-429 was underexpressed in neuroblastoma cells}

We first compared miR-429 expression in neuroblastoma cell lines and human neuronal cells. Our results showed that miR-429 expression was significantly lower in neuroblastoma cell lines than in normal cells (Fig. 1a).

Interestingly, IKK $\beta$ and NF- $\mathrm{BB}$ also showed differential expression between neuroblastoma cell lines and human neurons. The expressions of both were significantly higher in neuroblastoma cell lines (Fig. 1b through d). Furthermore, neuroblastoma patients with higher NF- $\mathrm{KB}$ and IKK $\beta$ expressions had a poorer prognosis than those with lower NF-KB and IKK $\beta$ expressions (Fig. 1e and f). These results suggest that miR-429 and IKK $\beta$ play an important role in the development of neuroblastoma. 


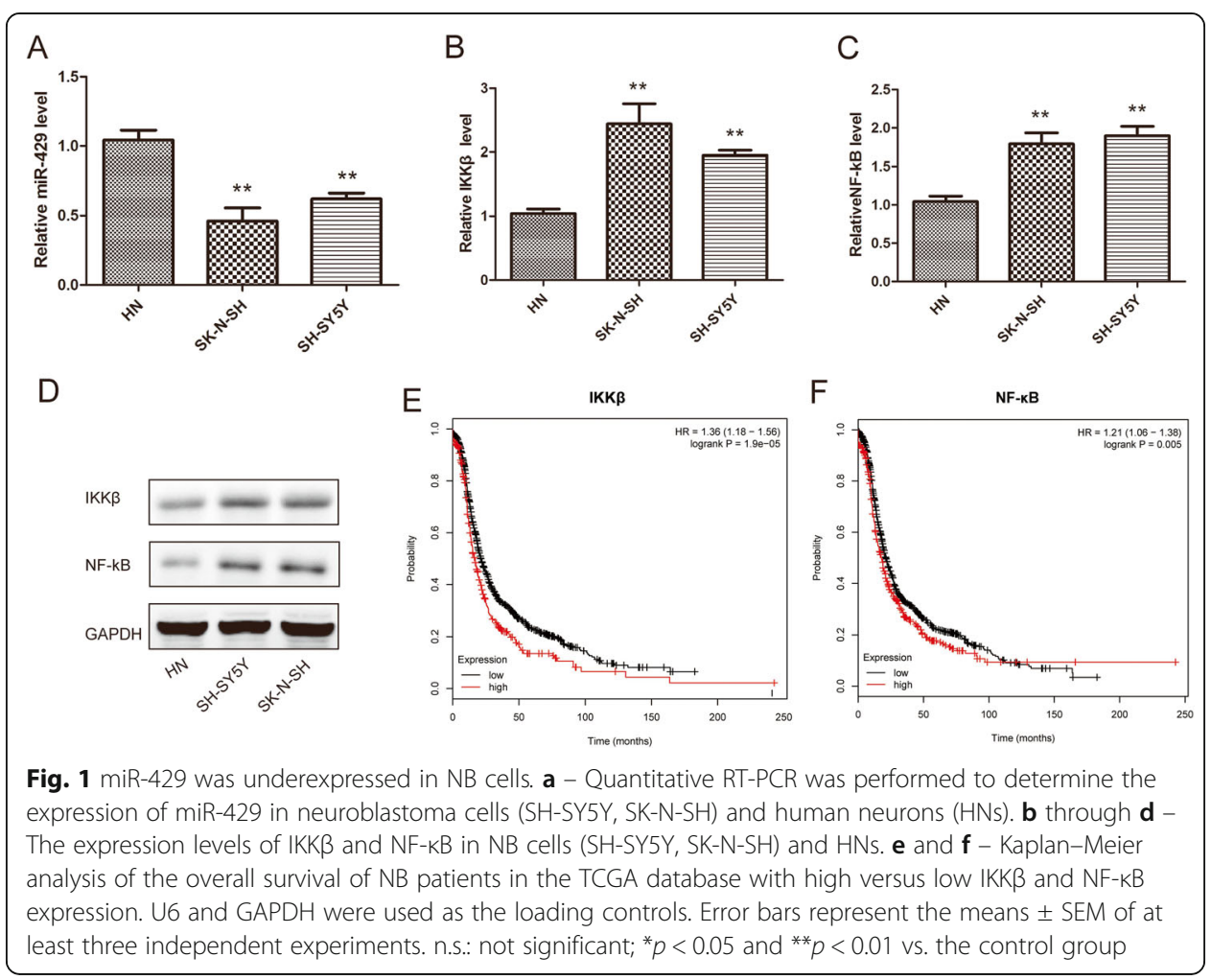

miR-429 inhibition accelerates the proliferation, migration and invasion of neuroblastoma cells in vitro

We then knocked down miR-429 in SK-SY5Y and SK-N-SH cells. The expression of miR429 was significantly downregulated at the RNA level (Fig. 2a). Colony formation assays showed that miR-429 inhibition significantly increased the rate of cell proliferation (Fig. 2b). Scratch and invasion assay results showed that the cell migration capability significantly increased after transfection with the miR-429 inhibitor (Fig. 2c). A Matrigel invasion assay also showed that the invasion capacities of SK-SY5Y and SK-N-SH cells significantly increased after transfection with the miR-429 inhibitor (Fig. 2d). The apoptosis assessment results demonstrated that miR-429 knockdown suppressed SK-SY5Y and SK-N-SH cell apoptosis (Fig. 2e). These results suggest that miR-429 can suppress the progression of neuroblastoma.

miR-429 overexpression blocked the proliferation, migration and invasion of neuroblastoma cells in vitro

Next, SK-SY5Y and SK-N-SH cells were transfected with the miR-429 mimic. The miR-429 level was significantly higher in the transfected cells (Fig. 3a). Furthermore, colony formation assays showed that the cell proliferation rate was inhibited (Fig. 3b). Similarly, scratch and invasion assays indicated that miR-429 overexpression inhibited the migration and invasion abilities of SH-SY5Y and SK-N-SH cells (Fig. 3c and d). Flow cytometric analysis indicated that miR-429-transfected SH-SY5Y and SK-N-SH cells exhibited an enhanced apoptosis rate compared with control cells (Fig. 3e) These results further demonstrate that miR-429 is able to suppress neuroblastoma progression. 




\section{IKK $\beta$ was identified as a target gene of miR-429}

Based on miR target analysis using the websites targetscan, PicTar and miRanda, miR-429 was found to be a potential regulator of IKK $\beta$ (Fig. 4a). Luciferase reporter assays showed that miR-429 overexpression can decrease the luciferase activity of the wild-type (Wt) 3'-UTR of IKK $\beta$ but did not affect luciferase activity of the mutant (Mut; Fig. 4b). Moreover, in SH-SY5Y, SK-N-SH and IMR-32 cells, the expression of IKK $\beta$ was regulated by miR-429 at the mRNA and protein level. Our results showed that the miR-429 mimic significantly inhibited the expression of 


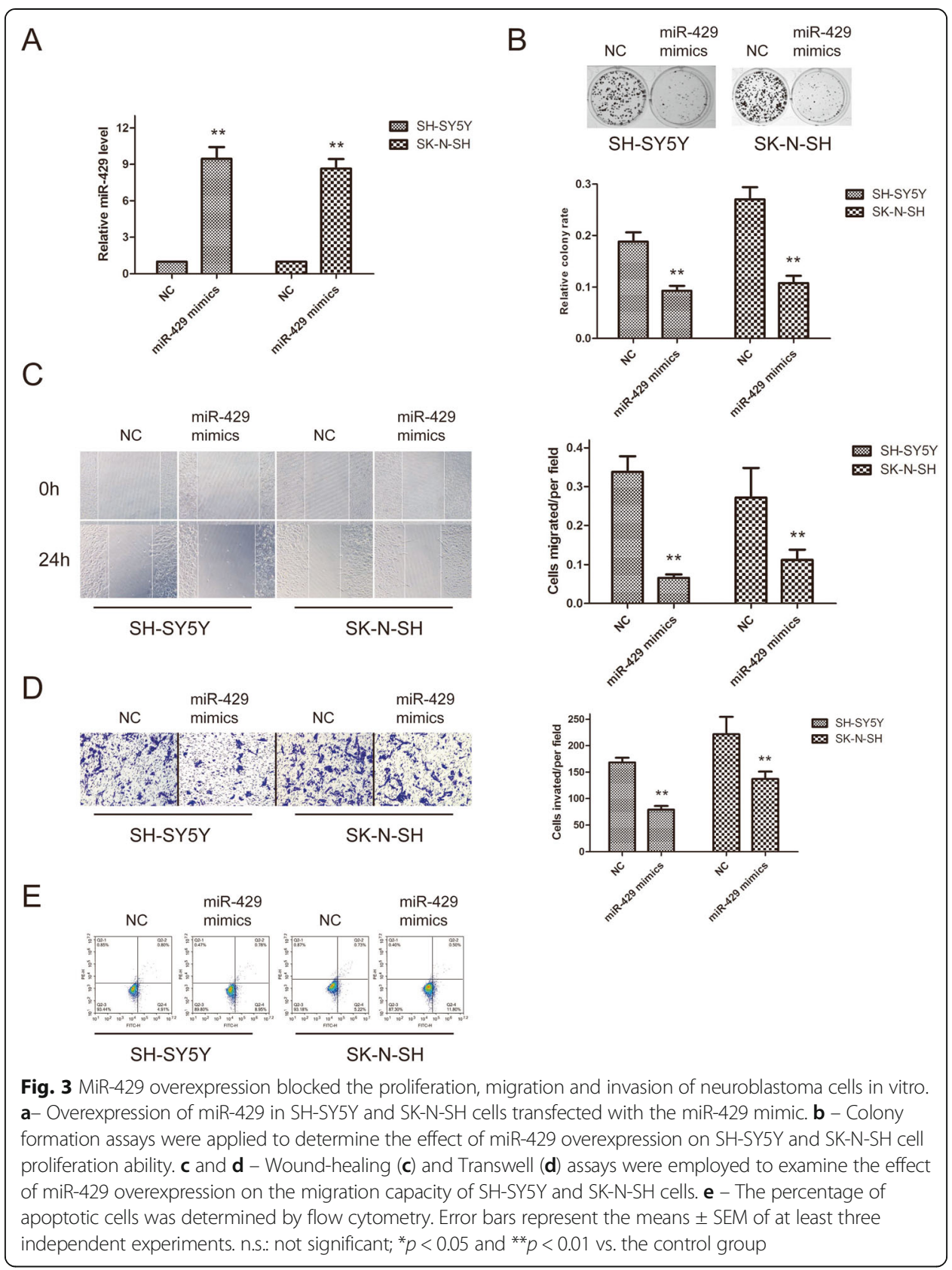

IKK $\beta$ (Fig. 4c and e), whereas silencing of miR-429 significantly increased IKK $\beta$ expression (Fig. $4 \mathrm{~d}$ and f). These data suggest that IKK $\beta$ is a target of miR-429 in neuroblastoma cells.

\section{miR-429 inhibited the NF-KB pathway}

We investigated the molecular mechanisms that may be involved in the anticancer effects of miR-429. The NF-kB signaling pathway is often found to be abnormally activated in neuroblastoma, promoting cell proliferation and inhibiting apoptosis [25, 26]. We explored whether miR-429 regulates NF- $\mathrm{kB}$ activity. 




The mRNA expression levels of three NF- $\kappa B$ target genes were significantly lower in SH-SY5Y, SK-N-SH and IMR-32 cells transfected with the miR-429 mimic (Fig. 5a, c and e). Under the same conditions, the protein expression of the NF- $\mathrm{kB}$ target genes cyclin D1, Bcl-2 and IL8 was lower in SH-SY5Y, SK-N-SH and IMR-32 cells (Fig. 5b, d and $\mathrm{f}$ ).

Further investigations were performed to study whether overexpression of IKK $\beta$ could attenuate the anticancer effect of miR-429. MTT assays showed that overexpression of IKK $\beta$ could significantly attenuate the anticancer effect of miR-429 in SH-SY5Y and SK-N-SH cells (Fig. $5 \mathrm{~g}$ and h), suggesting that miR-429 inhibited the proliferation of neuroblastoma cells in part by targeting IKK $\beta$. 


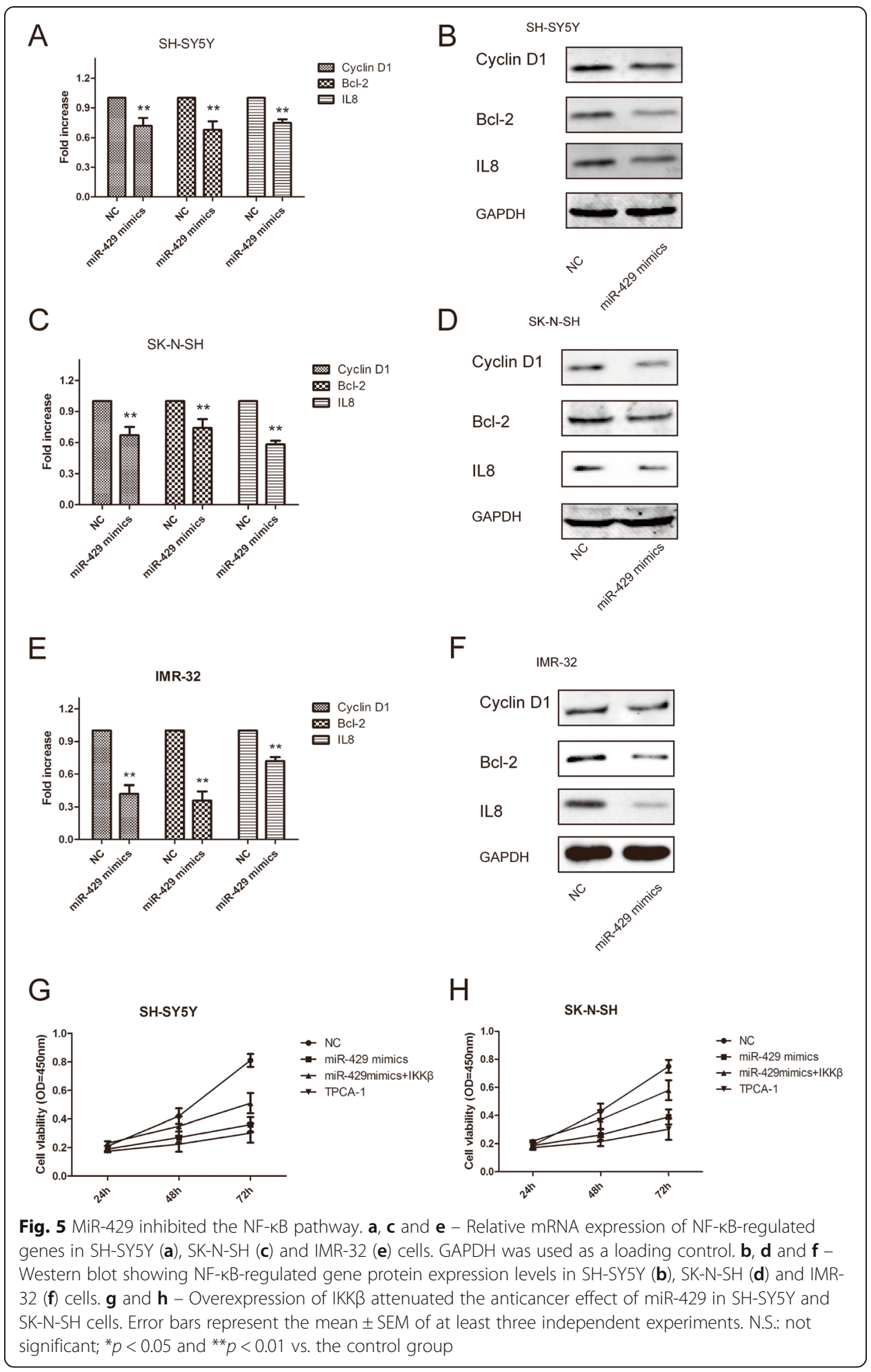

We then treated neuroblastoma cells with the IKKB inhibitor TPCA-1 and obtained the same results as observed after transfection with the miR-429 mimic. Our results indicate that IKK $\beta$ plays an important role in miR-429-mediated NF-kB activation. 


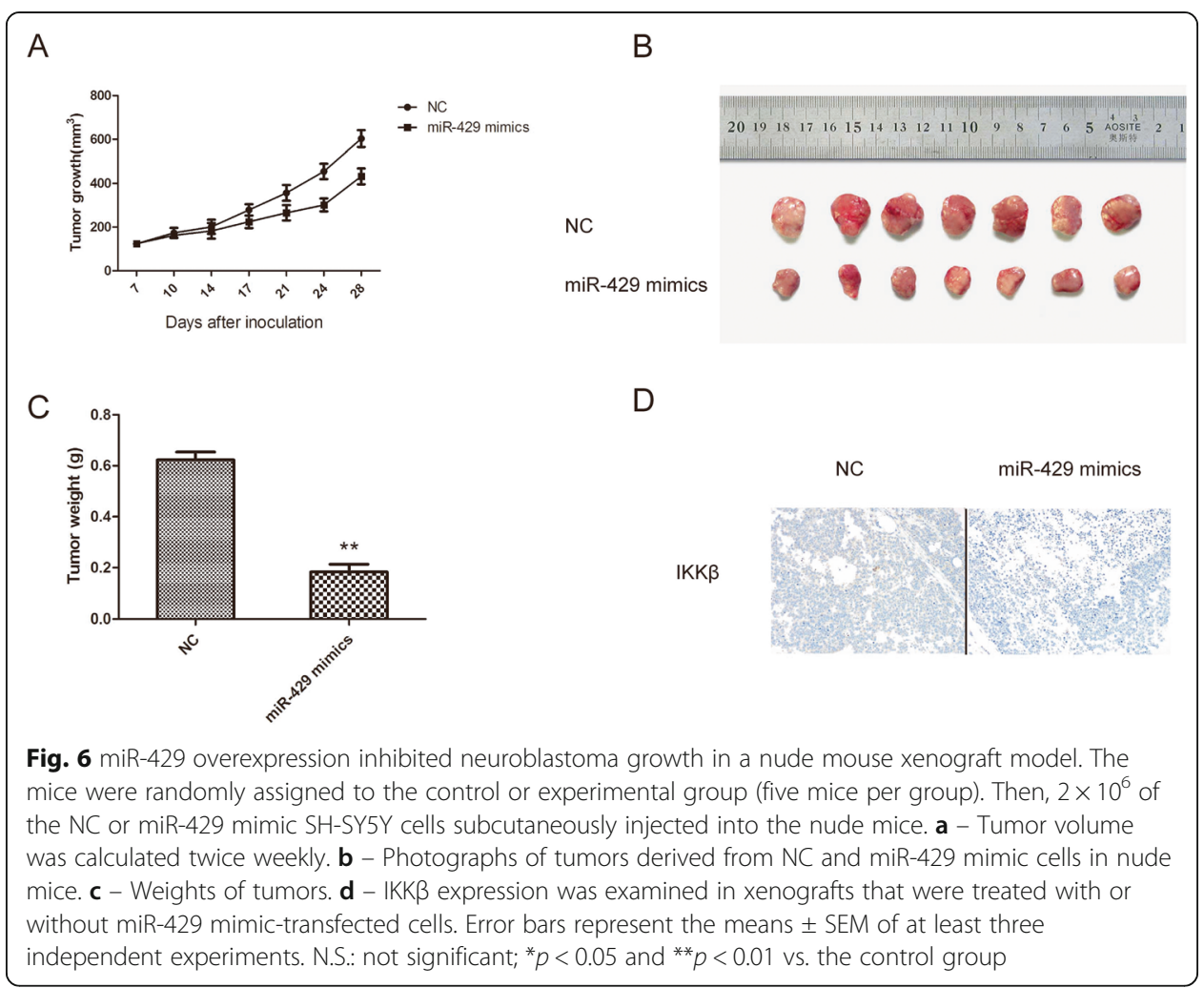
miR-429 overexpression inhibits neuroblastoma growth in a nude mouse xenograft
model

To address the role of miR-429 in neuroblastoma tumorigenesis in vivo, we established miR-429 SH-SY5Y stable cell lines (miR-429 mimics) to study their biological functions in a murine model. We initiated tumor growth by subcutaneously injecting $2 \times 10^{6}$ miR-429 mimics cells into BALB/c mice and monitored tumor growth by measuring the dimensions.

The tumors formed from SH-SY5Y cells transfected with the miR-429 mimic grew significantly more slowly than those from control cells and had lower weights (Fig. 6a through $\mathrm{c}$ ).

In addition, immunohistochemical staining was performed to determine the expression of IKK $\beta$ in mouse tumor tissues. IKK $\beta$ expression decreased in the xenograft tumors after treatment with the miR-429 mimics (Fig. 6d). These data suggest that miR429 plays an important role in the development of neuroblastoma.

\section{Discussion}

Despite advances in treatment, there have been limited improvements in the survival of patients with neuroblastoma. This is mainly due to a lack of early detection methods. In recent years, studies of epigenetic biomarkers, such as miRNA expression, suggest that epigenetic changes may be linked to neuroblastoma. It has been reported that miRNAs are involved in a variety of cellular processes and diseases through direct binding to the 3'-UTR of target mRNAs. Understanding the role of miRNAs that are aberrantly expressed in neuroblastoma can help us to understand the underlying mechanisms and improve therapeutic approaches. 
In this study, we evaluated the expression level of miR-429 in neuroblastoma cells and human neurons. Our results suggest that miR-429 may play an important role in cervical carcinogenesis. We showed that overexpression of miR-429 could obviously inhibit neuroblastoma cell metastasis ability and proliferation, while knockdown of miR429 had the opposite effects. This shows that miR-429 might have critical roles in neuroblastoma cells.

MiR-429 was found to play an oncogenic role in various endometrial carcinomas. However, miR-429 was also found to have a tumor-suppressive role in some cancers. For example, miR-429 inhibited the proliferation and migration of gastric cancer cells [28-30]. These suppression results are consistent with our results in neuroblastoma.

The IKK complex directly activates NF- $\kappa B$, which is regulated by miRNAs. The canonical IKK complex consists of three major subunits: IKK $\alpha$, IKK $\beta$, and IKK $\gamma$. A large number of studies have shown that IKK $\beta$ is associated with the occurrence of a variety of tumors. It has been reported that $I K K \beta$ is negatively regulated by miR199a [31] and IKK $\alpha$ is negatively regulated by miR-16 [32] to reduce NF-кB activity.

In our study, we demonstrated that IKK $\beta$ promotes oncogenic activity and may mediate the effects of miR-429 on malignancy. We confirmed potential binding sites between miR-429 and IKK $\beta$ through bioinformatics analysis. Luciferase reporter assays indicated that miR-429 can bind to the 3 '-UTR region of IKK $\beta$. We then found that miR-429 overexpression could decrease the expression of IKK $\beta$ at the mRNA and protein level. MTT assays showed that overexpression of IKK $\beta$ could significantly attenuate the anticancer effect of miR-429. The mRNA and protein expressions of the three NF- $\mathrm{kB}$ target genes significantly decreased in SH-SY5Y and SK-N-SH cells transfected with the miR-429 mimic.

Based on this, we speculate that miR-429 may influence the activation of the IKK $\beta$ / $\mathrm{NF}-\kappa \mathrm{B}$ pathway. We revealed that during the activation of the NF- $\mathrm{B}$ pathway, miR429 reduced the level of activated NF- $\mathrm{KB}$ by suppressing IKK $\beta$. It has been reported that many other signaling pathways are also involved in tumor migration and other processes, such as the Wnt signaling pathway [33, 34]. Whether there are other signaling pathways involved in neuroblastoma is a question worth exploring.

\section{Conclusion}

Our results show that miR-429 inhibits neuroblastoma progression by downregulating the NF- $\mathrm{kB}$ signaling pathway. These are novel insights into how miR-429 serves as a tumor suppressor by targeting IKK $\beta$ and attenuating NF- $\mathrm{KB}$ activity. Furthermore, this may indicate that miR-429 is a new target for neuroblastoma therapy.

Abbreviations

IKK: I kappa B kinase; Mut: Mutant; Wt: Wild-type

Acknowledgments

Not applicable.

$X J Z, H T L, Q D$ and XC designed the study, carried out the experiments and drafted the manuscript; FJL, XWH, and LLH participated in the experiments and data analysis. XJZ and HTL contributed equally to this work. All authors read and approved the final manuscript. 


\section{Funding}

This work was supported by the National Natural Science Foundation of China Youth Science Foundation (grant nos. 81502363 and 81602395).

\section{Availability of data and materials}

Datasets used and/or analyzed in this study can be obtained from the corresponding author on reasonable request.

\section{Ethics approval and consent to participate}

The ethics committee of Qingdao University approved the research. All experiments were performed in strict accordance with the principles of the Declaration of Helsinki Declaration. The agreed trial date was August 10, 2018, and the approval number is 2018810

\section{Consent for publication}

Not applicable.

\section{Competing interests}

The authors declare that they have no competing interests.

\section{Author details}

'Department of Pediatric Surgery, the Affiliated Hospital of Qingdao University, No.16 Jiangsu Road, Qingdao 266000, Shandong, China. ${ }^{2}$ Department of Operation Room, the Affiliated Hospital of Qingdao University, No.59 Haier Road, Qingdao 266000, Shandong, China.

Received: 24 June 2019 Accepted: 31 January 2020

Published online: 13 February 2020

\section{References}

1. Maris JM, Hogarty MD, Bagatell R. Neuroblastoma. Lancet. 2007:369(9579):2106-20.

2. Oldridge DA, Wood AC, Weichertleahey N. Genetic predisposition to neuroblastoma mediated by a LMO1 superenhancer polymorphism. Nature. 2015:528(7582):418.

3. Pugh TJ, Morozova O, Attiyeh EF, Crimmins I, Sussman R, Winter C. The genetic landscape of high-risk neuroblastoma. Nat Genet. 2013:45(3):279-84

4. Ward E, Desantis C, Robbins A, Kohler B, Jemal A. Childhood and adolescent cancer statistics. Ca A Can J Clin. 2014; 64(2):83-103.

5. Westermann F, Schwab M. Genetic parameters of neuroblastomas. Cancer Lett. 2002;184(2):127-47.

6. Park JR, Bagatell R, London WB. Children's oncology Group's 2013 blueprint for research: neuroblastoma. Pediatr Blood Cancer. 2013;60(6):1016-21.

7. Daniels JL, Olshan AF, Teschke K, Hertz-Picciotto I, Savitz DA, Blatt J. Residential pesticide exposure and neuroblastoma. Epidemiology. 2001:12(1):20-7.

8. Pacifico F, Leonardi A. NF-kappaB in solid tumors. Biochem Pharmacol. 2006;72(9):1142.

9. Xiong $\mathrm{S}$, Wang $\mathrm{Y}$, Li H, Zhang X. Low dose of Bisphenol a activates NF-KB/IL-6 signals to increase malignancy of neuroblastoma cells. Cell Mol Neurobiol. 2017;37(6):1095-103.

10. Karin M, Delhase M. The I kappa B kinase (IKK) and NF-kappa B: key elements of proinflammatory signaling. Semin Immunol. 2000;12:85-98.

11. Hayden MS, Ghosh S. Signaling to NF-KB. Genes Dev. 2004;18(18):2195-224.

12. Häcker H, Karin M. Regulation and Function of IKK and IKK-Related Kinases. Sci STKE. 2006;2006(357):re13.

13. Kaisho T, Tanaka T. Turning NF-KB and IRFs on and off in DC. Trends Immunol. 2008;29(7):0-336.

14. Yu J, Wang L, Zhang T, Shen H, Dong W, Ni Y. Co-expression of $\beta$-arrestin1 and NF-KB is associated with cancer progression and poor prognosis in lung adenocarcinoma. Tumour Biol. 2015;36(8):6551-8.

15. Karin M. Nuclear factor-kappaB in cancer development and progression. Nature. 2006:441(7092):431-6.

16. Luo JL, Kamata H, Karin M. IKK/NF-KB signaling: balancing life and death - a new approach to cancer therapy. J Clin Investig. 2005;115(10):2625.

17. Kasibhatla S, Brunner T, Genestier L, Echeverri F, Mahboubi A, Green DR. DNA damaging agents induce expression of Fas ligand and subsequent apoptosis in T lymphocytes via the activation of NF-kappa B and AP-1. Mol Cell. 1998;1(4): 543

18. Mayo MW, Baldwin AS. The transcription factor NF-kappaB: control of oncogenesis and cancer therapy resistance. Biochim Biophys Acta. 2000;1470(2):M55-62.

19. Meteoglu I, Erdogdu IH, Meydan N, Erkus M, Barutca S. NF-KappaB expression correlates with apoptosis and angiogenesis in clear cell renal cell carcinoma tissues. J Exp Clin Cancer Res. 2008;27(1):53.

20. Schmiedel JM, Klemm SL, Zheng Y, Sahay A. MicroRNA control of protein expression noise. Science. 2015;348(6230):12832.

21. Martinezsanchez A, Murphy CL. miR-1247 functions by targeting cartilage transcription factor SOX9. J Biol Chem. 2013; 288(43):30802-14.

22. Liu X, Peng H, Liao W, Luo A, Cai M, He J. miR-181a/b Induces the Growth, Invasion and Metastasis of Neuroblastoma Cells Through Targeting ABI1. Mol Carcinog. 2018;57:1237-50.

23. Pereira DM, Rodrigues PM, Borralho PM. Delivering the promise of miRNA cancer therapeutics. Drug Discov Today. 2013; 18(5-6):282-9.

24. Wu T, Lin Y, Xie Z. MicroRNA-1247 inhibits cell proliferation by directly targeting ZNF346 in childhood neuroblastoma. Biol Res. 2018;51(1):13.

25. Sun T, Wang C, Xing J, Wu D. miR-429 modulates the expression of c-myc in human gastric carcinoma cells. Eur J Cancer. 2011;47(17):2552-9. 
26. Ye ZB, Ma G, Zhao YH, Xiao Y, Zhan Y, Jing C. miR-429 inhibits migration and invasion of breast cancer cells in vitro. Int J Oncol. 2015;46(2):531-8.

27. Deng Y, Luan F, Zeng L, Zhang Y, Ma K. MiR-429 suppresses the progression and metastasis of osteosarcoma by targeting ZEB1. EXCLI J. 2017;16:618-27.

28. Liu D, Xia P, Diao D, Cheng Y, Zhang H, Yuan D. MiRNA-429 suppresses the growth of gastric cancer cellsin vitro. J Biomed Res. 2012;26(5):389-93.

29. Liu W, An J, Li K, Hou H. MiR-429 regulates gastric cancer cell invasiveness through ZEB proteins. Tumour Biol J Int Soc Oncodevelopmental Biol Med. 2015;37(12):15575-81.

30. Zhang M, Dong BB, Lu M, Zheng MJ, Chen H, Ding JZ, et al. miR-429 functions as a tumor suppressor by targetingFSCN1 in gastric cancer cells. Oncotargets \& Therapy. 2016;9(1):1123-33.

31. Chen R, Alvero AB, Silasi DA, Kelly MG, Fest S, Visintin I. Regulation of IKK 3 by miR-199a affects NF-KB activity in ovarian cancer cells. Oncogene. 2008;27(34):4712.

32. Shin VY, Jin $\mathrm{H}, \mathrm{Ng}$ EK, Cheng AS, Chong WW, Wong CY. NF-KB targets miR-16 and miR-21 in gastric cancer: involvement of prostaglandin E receptors. Carcinogenesis. 2011;32(2):240-5.

33. Arabzadeh S, Hossein G, Dulabi ZS, Zarnani AH. WNT5A-ROR2 is induced by inflammatory mediators and is involved in the migration of human ovarian cancer cell line SKOV-3. Cell Mol Biol Lett. 2016;21(1).

34. Kim S, Cheon H, Kim SM, Kim YY. GSK-3ß-mediated regulation of cadmium-induced cell death and survival. Cell Mol Biol Lett. 2018;23(1):9.

\section{Publisher's Note}

Springer Nature remains neutral with regard to jurisdictional claims in published maps and institutional affiliations.

\section{Ready to submit your research? Choose BMC and benefit from:}

- fast, convenient online submission

- thorough peer review by experienced researchers in your field

- rapid publication on acceptance

- support for research data, including large and complex data types

- gold Open Access which fosters wider collaboration and increased citations

- maximum visibility for your research: over $100 \mathrm{M}$ website views per year

At $\mathrm{BMC}$, research is always in progress. 